\title{
Electrical stimulation and isokinetic training: effects on strength and neuromuscular properties of healthy young adults
}

\author{
Estimulação elétrica e treinamento isocinético: efeitos na força e propriedades \\ neuromusculares de adultos jovens sadios
}

Avila MA', Brasileiro JS², Salvini TF'

\begin{abstract}
Objective: To assess the effects of neuromuscular electrical stimulation (NMES) associated with an isokinetic training program in healthy young men and women. Methods: Twenty participants (ten men, ten women; $21 \pm 1.5$ years) underwent an isokinetic training program for knee extensors of both sides (three sets of ten concentric repetitions at $30 \%$ s) twice a week for four weeks. One limb underwent only the isokinetic strength training (Ex) while the other underwent the same training but with NMES associated with each contraction (Ex+NMES). The current used for NMES was the Russian current (frequency of $2,500 \mathrm{~Hz}, 50$ bursts/s and pulse duration of $200 \mu s$ ). Isometric and isokinetic concentric extensor torque at $30 \%$ s were evaluated. Results: The groups increased their peak torque in both test procedures, with no difference between Ex and Ex+NMES. The angle of peak torque increased for the Ex limb, thus showing a change in the tension-length relationship of the muscle group tested, which did not occur for the Ex+NMES limb. There was also a decrease in acceleration time in both limbs, without any effects from NMES on this variable. Conclusions: These results showed that the association between NMES and isokinetic concentric voluntary strength training did not improve the strength gains and neuromuscular properties of voluntary strength training itself for healthy young participants of both genders.
\end{abstract}

Article registered in the ClinicalTrials.gov under the number NCT00512018.

Key words: electric stimulation; quadriceps muscle; muscle strength; neuromuscular properties; tension-length relationship.

\section{Resumo}

Objetivo: Verificar os efeitos da estimulação elétrica neuromuscular (EENM) associada a um programa de treinamento isocinético em homens e mulheres jovens e sadios. Métodos: Vinte indivíduos (dez homens, dez mulheres, 21 $\pm 1,5$ anos) submeteram-se a um programa de treinamento isocinético de ambos os seus extensores de joelho (três séries de dez repetições concêntricas a $30 \%$ s) duas vezes por semana por quatro semanas. Um membro foi submetido apenas ao treinamento de força isocinético (Ex) enquanto o outro foi submetido ao mesmo treinamento, mas com EENM associada a cada contração (Ex+EENM). A corrente utilizada para a EENM foi a corrente russa (frequência de $2.500 \mathrm{~Hz}, 50$ bursts/s, duração de pulso de $200 \mu \mathrm{s}$ ). O protocolo de avaliação incluiu o torque extensor isométrico e isocinético concêntrico a 30\%. Resultados: Os grupos aumentaram seu pico de torque em ambas as modalidades testadas, sem diferença entre Ex e Ex+EENM. O ângulo do pico de torque aumentou para o membro Ex, mostrando uma alteração da relação comprimento-tensão do grupo muscular testado, o que não aconteceu com o membro Ex+EENM. Houve também uma diminuição no tempo de aceleração de ambos os membros, sem efeito da EENM sobre este parâmetro. Conclusões: Estes resultados mostraram que a associação entre a EENM e o treinamento voluntário isocinético concêntrico não melhorou os ganhos de força e de propriedades neuromusculares do próprio treinamento de força voluntário para sujeitos jovens e sadios de ambos os gêneros.

Artigo registrado no ClinicalTrials.gov sob o número NCT00512018.

Palavras-chave: estimulação elétrica; músculo quadríceps; força muscular; propriedades neuromusculares; relação comprimentotensão. 


\section{Introduction $: \therefore$.}

The isokinetic concept of exercise began in late 1960s and today isokinetic dynamometers are widely used to assess and improve muscle function for both rehabilitation and training purposes $^{1-4}$. The widespread application of isokinetic dynamometers relates to their ability to accurately quantify muscle function through the total range of movement at constant velocity. Thus, this system allows maximal muscle contractions and enables measurements with high reproducibility ${ }^{1-3}$. Several authors have already stated the importance of isokinetic strength training in diseased ${ }^{4}$, healthy ${ }^{1-3}$ and athletic ${ }^{5}$ populations.

Electrical stimulation is extensively used in physical therapy. The ability of neuromuscular electrical stimulation (NMES) protocols to improve the skeletal muscle performance of healthy muscles ${ }^{1-3,6}$ has been accepted and demonstrated both in research studies and in rehabilitation practice ${ }^{4,7}$. Unfortunately, the abundance of muscle stimulators and NMES protocols in clinics appears to contrast sharply with the availability and quality of evidence regarding their efficacy. The available evidence is of limited quality and needs to be interpreted with caution ${ }^{8-10}$.

Strength training is routinely used in rehabilitation and sports activities to improve musculoskeletal performance. Since the studies by Dr. Yakov Kots, NMES and especially Russian current have been considered to be another type of strength training, together with voluntary contractions ${ }^{10,11}$. Several studies have found that NMES and voluntary exercises are equally effective in increasing the strength of the quadriceps femoris muscle in healthy individuals ${ }^{12-14}$; while others have found $\mathrm{NMES}^{15-18}$ to be more effective. Comparisons between studies are not always possible because of variations in NMES and exercise protocols. Some studies have used NMES and exercises separately ${ }^{16,17}$, while others have used NMES superimposed on voluntary contractions ${ }^{9,13}$.

Attempts have been made to combine training involving NMES and voluntary actions, with special attention to isometric and isokinetic actions. Westing, Seger and Thorstensson ${ }^{19}$ found that NMES increased knee extensor torque for eccentric contractions, whether applied to the relaxed muscle or superimposed on maximal voluntary contraction. However, Currier and $\mathrm{Mann}^{13}$ and Kramer and Semple ${ }^{20}$ showed that volitional training was more effective than independent NMES or superimposed NMES for increasing quadriceps femoris torque. Although many studies have raised this issue, the conclusions are always controversial and comparisons are difficult because of methodological differences.

Thus, the purpose of this study was to evaluate the effects of the combination of NMES and isokinetic training among healthy young men and women. We hypothesized that NMES could improve the strength gains and modify the neuromuscular changes achieved through isokinetic training.

\section{Methods : :}

\section{Participants}

Twenty active and healthy undergraduate students (men: $21 \pm 1.9$ years; $1.77 \pm 0.1 \mathrm{~m} ; 73 \pm 8.4 \mathrm{~kg} ; 23.3 \pm 1.4 \mathrm{~kg} / \mathrm{m}^{2}$; women: $20.9 \pm 0.7$ years; $1.64 \pm 0.1 \mathrm{~m} ; 56.3 \pm 5.5 \mathrm{~kg} ; 21 \pm 1.0 \mathrm{~kg} / \mathrm{m}^{2}$ ) were selected for this study. All participants underwent physical examination before the study and had already participated in strength training programs. The inclusion criteria were that the participants had to be young (age range between 18 and 25 years), have normal body mass index (between 20 and $24.9 \mathrm{~kg} / \mathrm{m}^{2}$ ), avoid any other physical activity during the training period, have no neuromuscular disorders in the lower limbs, and no history of knee pain. The exclusion criteria were pregnancy, epilepsy, cancer, suspected heart disease, recent surgery, respiratory disorders, uncompensated diabetes, history of lower limb trauma, fracture or surgery, or reports of pain in the knee joints. All ten male participants who were selected concluded the study. In contrast, of the 15 women who were selected and began the training program, five were excluded: three reported episodes of pain in the knee joint during training sessions, and two of them could not conclude the training program for personal reasons. Therefore, the final data refers to ten women.

All of the evaluation and training procedures were explained before they began and all participants signed a consent statement. The project was approved by the Ethics Committee for Medical Research of Universidade Federal de São Carlos (Approval report number 067/03) and was in accordance with the Declaration of Helsinki.

\section{Evaluation protocol}

Before every evaluation, the participants familiarized themselves with the testing and training procedures. All of the evaluation and training procedures were applied to both the right and the left limbs before and after the training program. To avoid possible dominance effects, the volunteers were randomly distributed to determine the limb (right or left) that would receive NMES. The investigator who did the data analysis was blind to this randomization.

After a five-minute warm-up on a stationary bicycle at a speed of $20 \mathrm{~km} / \mathrm{h}$ and load of $20 \mathrm{~W}$, the participants stretched the quadriceps femoris and hamstring muscles of both limbs. Each muscle group was stretched three times for 30 seconds alternately.

Following the warm-up, the participants were positioned in an isokinetic dynamometer (Biodex ${ }^{\circledR}$ Multi-joint System 3, Biodex, Shirley, NY), with hip angle of $100^{\circ}$. The trunk, pelvis and thigh were stabilized using straps, in accordance with the 
equipment instructions. The rotation axis of the dynamometer was aligned with the axis of the knee, at the level of the lateral epicondyle of the femur, while it was attached to the distal part of the leg, about $5 \mathrm{~cm}$ above the medial malleolus. A gravity effect correction was calculated with the limb at $60^{\circ}$ flexion. The isokinetic device was calibrated before each evaluation and training session, as recommended by the manufacturer.

Following this, the participants had their knees positioned at $60^{\circ}$ and were familiarized with the procedures. They were then asked to perform three maximal voluntary isometric knee extension contractions for five seconds, with one-minute rest intervals between contractions. Three minutes after the last isometric contraction, the participants were familiarized with the isokinetic contraction and then performed five maximal isokinetic concentric knee extension contractions at a speed of $30^{\circ} / \mathrm{s}$, from $90^{\circ}$ to $15^{\circ}$ ( $0^{\circ}$ being full extension), totaling $75^{\circ}$ of range of motion (ROM). Verbal encouragement, as well as visual feedback from the equipment, was given in an attempt to achieve maximal voluntary effort level during all the contractions that each participant was asked to perform. The same procedures were repeated with the contralateral limb.

\section{Isokinetic training protocol}

The training program started between the second and the fifth day after the initial evaluation. The participants performed training sessions twice a week with a two-day minimum interval between the sessions for four weeks. Each session included a five-minute warm-up period on a stationary bicycle, followed by three sets of quadriceps stretching as previously described. After being placed in the same position as in the evaluation sessions on the isokinetic dynamometer, the participants performed three sets of ten maximal isokinetic concentric repetitions, at the speed of $30^{\circ} / \mathrm{s}$, with one limb (Ex), observing a resting period of three minutes between the sets. For the contralateral limb, the same protocol was repeated; however, each contraction was associated with superimposed NMES (Ex+NMES).

\section{NMES of the quadriceps femoris muscle}

For NMES, a symmetric double-phase sine-wave current generator (Physiotonus Slim, Bioset, Brazil) was used. The carrier wave frequency was $2,500 \mathrm{~Hz}$, modulated at $50 \mathrm{bursts} / \mathrm{s}$, with a pulse duration of $200 \mu \mathrm{s}$ and an interburst interval of ten minutes. This configuration is known as Russian current. Two self-adhesive electrodes $(5 \times 13 \mathrm{~cm})$ were placed on the participant's thigh: one approximately $10 \mathrm{~cm}$ below the iliac anterosuperior spine in the proximal region of the quadriceps; and the other over the distal portion of the quadriceps femoris, about $5 \mathrm{~cm}$ above the suprapatellar line, over the belly of the vastus medialis obliquus muscle. At each training session, the amplitude of current used was the maximum each participant could tolerate. The stimuli were applied only during knee extensor contraction, therefore there was no NMES application during passive knee flexion.

\section{Data analysis}

Isometric and isokinetic peak torque (PT), angle of peak torque (APT) and acceleration time (AccT) were compared between men and women; between the Ex and Ex+NMES groups; before and after the training. We also analyzed the tolerated current amplitude for the stimulated group.

\section{Statistical analysis}

The software used for statistical analysis was Statistica 5.5 (StatSoft Inc., Tulsa, OK, USA). Data homogeneity was checked using Levene's homogeneity test. Because all the data were homogeneous two-way ANOVA with repeated measurements and Tukey's post hoc test were used to investigate whether there were any differences between groups and gender for the variables analyzed. One-way ANOVA with repeated measurements was used to investigate whether there were any differences in the current amplitude tolerated between the groups in each session.

\section{Results : :}

\section{Peak torque}

For the isometric mode, the men and women increased their PT $(\mathrm{p}<0.01)$ in both limbs with no difference between the Ex and Ex+NMES groups $(p>0.05)$. The men presented greater PT than the women following training $(p<0.01)$. NMES did not influence PT increases, either for the men or for the women ( $p>0.05)$. In the isokinetic mode, there was an increase in PT for both men and women $(\mathrm{p}<0.01)$, with no influence from gender or NMES ( $p>0.05)$, as seen in Figure 1.

\section{Angle of peak torque}

The men presented increased APT for the Ex limb in comparison with pre-training values: from $69.6^{\circ}$ to $73^{\circ}(\mathrm{p}<0.01)$. This did not occur for the Ex+NMES limb (from $69.8^{\circ}$ to $71.8^{\circ}$; $\mathrm{p}>0.05)$. The women also showed changes in their APT for the Ex limb (from $63.3^{\circ}$ to $67^{\circ} ; \mathrm{p}<0.01$ ); which did not occur for the Ex+NMES limb (from $64.9^{\circ}$ to $66.4^{\circ} ; \mathrm{p}>0.05$ ) (Figure 2). Gender did not influence this variable $(\mathrm{p}>0.05)$. 


\section{Acceleration time}

There was a decrease in AccT for both men and women after training $(\mathrm{p}<0.01)$, with no differences between these groups $(p>0.05)$. NMES did not affect this variable $(p>0.05)$ (Figure 3 ).

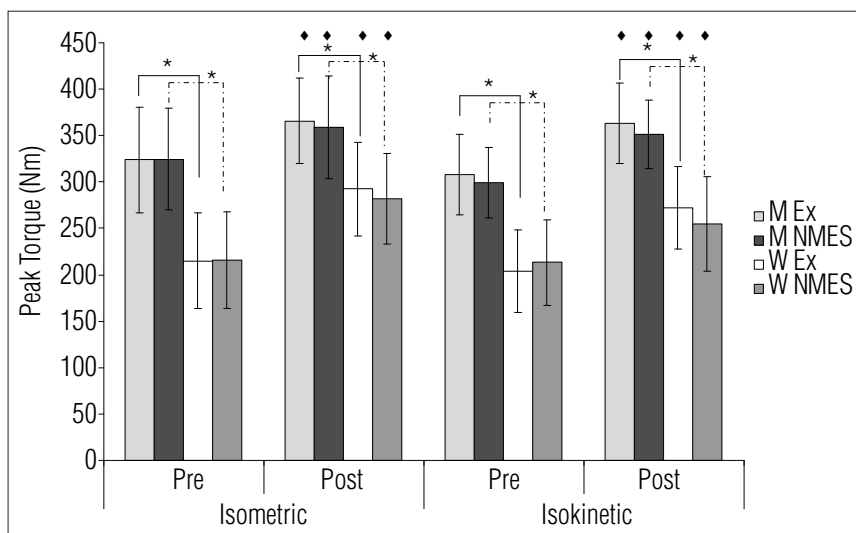

${ }^{*} p<0.01$ comparing men and women; $\bullet p<0.01$ comparing before and after training (pre and post).

Figure 1. Peak torque means (Nm) for men (M) and women (W) for both limbs, in the Ex and Ex+NMES (NMES) groups.

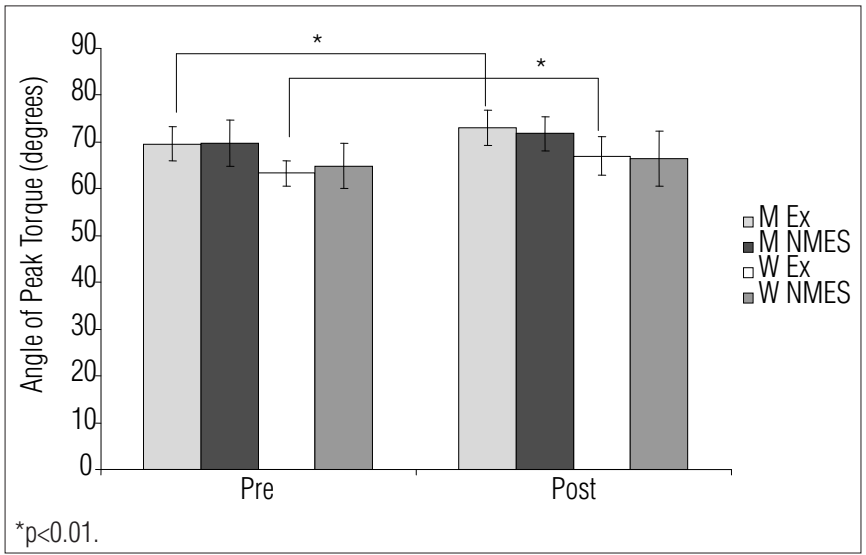

Figure 2. Angle of peak torque (in degrees) for men (M) and women (W) for both limbs, in the Ex and Ex+NMES (NMES) groups.

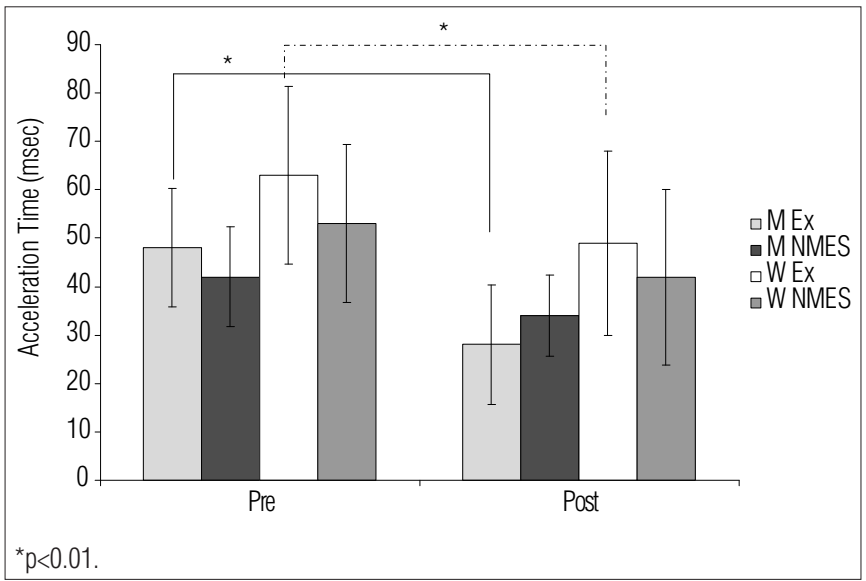

Figure 3. Acceleration time (in msec) for men (M) and women (W) for both limbs, in the Ex and Ex+NMES (NMES) groups.

\section{Tolerated current amplitude}

The current amplitude tolerated by the men increased from $40 \pm 9.2 \mathrm{~mA}$ (first session) to $76 \pm 20.7 \mathrm{~mA}$ (eighth session). The comparison between the first session and the subsequent sessions showed that, from as early as the interval between the first and second sessions, there was a significant difference and that this continued throughout the sessions. For the women, this increase went from $36 \pm 5 \mathrm{~mA}$ (first session) to $52 \pm 12.4 \mathrm{~mA}$ (eighth session). The comparison between the first session and the subsequent sessions showed that there was a significant difference between the first and third sessions, and that it continued throughout the sessions. Also, there was no difference between men and women for the first training session ( $p>0.05$ ); however, the men tolerated greater current amplitude than the women throughout most of the training sessions $(p<0.01)$, according to Figure 4.

\section{Discussion $: \because$.}

The main findings of this study were that (1) NMES associated with maximal concentric knee extension did not provide any additional torque increase, compared with voluntary concentric actions alone, in both healthy young men and women; (2) the concentric training increased not only the concentric torque, but also the isometric torque; (3) electrical stimulation did not contribute towards changes in the length-tension relationship for either the men or the women; (4) isokinetic training altered neuromuscular readiness for all the participants.

The limitations of this study include its small sample size, the fact that other isokinetic velocities were not tested, and the fact that both knee extensor groups were trained, which might have influenced the results due to cross-educational effects ${ }^{21}$.

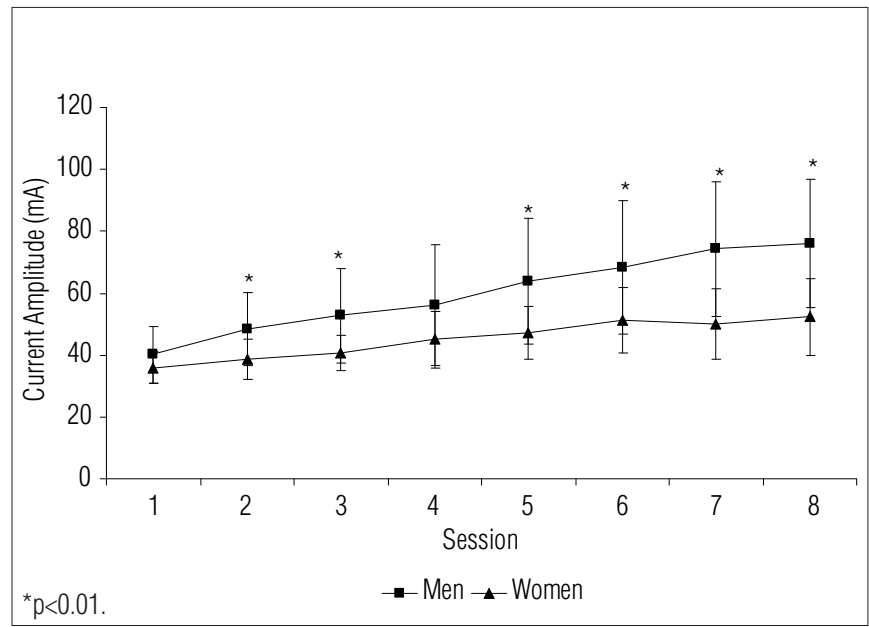

Figure 4. Tolerated current amplitude in $\mathrm{mA}$. 


\section{Peak torque}

The men and women increased their peak torque in both procedures tested, with no difference between the Ex and Ex+NMES groups. This result agrees with those of Requena Sánchez, Padial Puche and González-Badillo ${ }^{14}$, Brocherie et al. ${ }^{5}$, Maffiuletti et al..$^{22}$, Selkowitz ${ }^{16}$ and Paillard T, Noe F and Edeline ${ }^{23}$. Among healthy participants, NMES imposed simultaneously with volition did not recruit more motor units than did voluntary contractions alone, except for eccentric contractions. There is a consensus that the force increases induced by voluntary training associated with NMES are similar to, but not greater than, those induced by voluntary training ${ }^{14}$. Requena Sánchez, Padial Puche and González-Badillo ${ }^{14}$, in their review, found that the majority of the analyzed studies showed significant increases in isokinetic peak torque, whatever the chosen isokinetic velocity. Maffiuletti et al. ${ }^{22}$ found that short-term electrostimulation increased maximal voluntary strength by $12 \%$, which was accompanied by neural adaptations (cross-educational effect and increased muscle activation) and muscle adaptations in one healthy individual. The isokinetic training mode has been shown to induce strength gain in other modes ${ }^{21}$, and this agrees with our findings.

\section{Angle of peak torque}

Both groups increased their APT only for the Ex limb, meaning that they achieved their PT earlier within the ROM. This shows that, in this case, there was a change in the lengthtension relationship, according to Baron ${ }^{24}$. Provided that there is enough time for the contractile component of the muscle to develop its fullest capacity, the point at which PT occurs will remain constant ${ }^{24,25}$, thus indicating that the muscle can perform optimally at this joint position because of leverage and muscle length. According to Thorstensson, Grimby and Karlsson $^{26}$ and $\mathrm{Kannus}^{27}$, PT tends to occur at an increasingly late stage within the range of motion with higher angular velocities, and the weaker the muscle is, the later the PT occurs.

\section{Acceleration time}

The results showed decreased AccT for both the Ex and Ex+NMES groups. Therefore the NMES did not influence the improvement in neuromuscular readiness achieved with isokinetic training, either for men or for women. The acceleration period occurring during isokinetic tests may provide valuable information regarding neuromuscular readiness to produce maximal contraction $^{1}$. Miller et al. ${ }^{3}$ showed that isokinetic concentric training can decrease the acceleration time for women. Wolf et al. ${ }^{28}$ found that, although both experimental groups (exercise alone and NMES superimposed on exercise) improved significantly for all measurements (speed, strength and work), the electrical stimulation group did not produce changes of greater significance than those with resistive training alone. However, compared with a control group, the effect of electrical stimulation was more pronounced than the effect of training itself. After healthy participants undergo training programs, superimposed NMES appears to be as efficient as voluntary contractions in enhancing participants' neuromuscular qualities ${ }^{23}$.

\section{Tolerated current amplitude}

Both the men and the women increased tolerated amplitudes, possibly because of sensory accommodation mechanisms. This was in agreement with the results of Currier, Lehman and Lightfoot $^{12}$, Laughman et al. ${ }^{15}$, Selkowitz ${ }^{16}$, Soo, Currier and Threlkeld ${ }^{17}$, Lieber and Kelly ${ }^{6}$, Ward and Shkuratova ${ }^{11}$, Bax L, Staes F and Verhagen ${ }^{8}$, Requena Sánchez, Padial Puche and González-Badillo ${ }^{14}$ and Paillard et al. ${ }^{9}, 23$. Men were able to tolerate greater amplitudes than women. This was probably due to the differences in fiber type composition between men and women ${ }^{29}$.

\section{Practical applications for physical therapy and strength training}

For strength training, these results do not support the use of NMES combined with volitional efforts among healthy individuals, since the results from NMES are similar to those achieved with only volitional efforts. Nevertheless, when treating acute neuromuscular conditions such as those of early rehabilitation from any surgery, NMES can be of great help in reducing pain and edema, increasing ROM and improving muscle function ${ }^{30}$.

\section{Conclusions $: \because$.}

The results of this study found that the association between NMES and isokinetic concentric voluntary strength training did not improve strength gains of voluntary training alone for healthy young participants of both genders.

\section{Acknowledgements $: \because$.}

We are grateful for the grant support of the Brazilian agencies for science: Fundação de Amparo à Pesquisa do Estado de São Paulo (FAPESP) and Conselho Nacional de Desenvolvimento Científico e Tecnológico (CNPq). MA Avila was an undergraduate fellow from CNPq, and JS Brasileiro was a $\mathrm{PhD}$ fellow from Coordenação de Aperfeiçoamento de Pessoal de Nível Superior (CAPES), Brazil. We are also grateful to Olga M.S.F. Pinto (PT), Christiane R. Ivo (PT), Lara Paixão (PT) and Daniela Hanashiro (PT) for their help in data collection. 


\section{References $: \because$.}

1. Chen WL, Su FC, Chou YL. Significance of acceleration period in a dynamic strength testing study. J Orthop Sports Phys Ther. 1994;19(6):324-30.

2. Croisier JL, Malnati M, Reichard LB, Peretz C, Dvir Z. Quadriceps and hamstring isokinetic strength and electromyographic activity measured at different ranges of motion: a reproducibility study. J Electromyogr Kinesiol. 2007;17(4):484-92.

3. Miller LE, Pierson LM, Nickols-Richardson SM, Wootten DF, Selmon SE, Ramp WK et al. Knee extensor and flexor torque development with concentric and eccentric isokinetic training. Res Q Exerc Sport. 2006;77(1):58-63.

4. Eyigor S, Hepguler S, Capaci K. A comparison of muscle training methods in patients with knee osteoarthritis. Clin Rheumatol. 2004;23(2):109-15.

5. Brocherie F, Babault N, Cometti G, Maffiuletti N, Chatard JC. Electrostimulation training effects on the physical performance of ice hockey players. Med Sci Sports Exerc. 2005;37(3):455-60.

6. Lieber RL, Kelly MJ. Factors influencing quadriceps femoris muscle torque using transcutaneous neuromuscular electrical stimulation. Phys Ther. 1991;71(10):715-21.

7. Gregory CM, Bickel CS. Recruitment patterns in human skeletal muscle during electrical stimulation. Phys Ther. 2005;85(4):358-64.

8. Bax L, Staes F, Verhagen A. Does neuromuscular electrical stimulation strengthen the quadriceps femoris? A systematic review of randomised controlled trials. Sports Med. 2005;35(3):191-212.

9. Paillard T, Noé F, Passelergue P, Dupui P. Electrical stimulation superimposed onto voluntary muscular contraction. Sports Med. 2005;35(11):951-66.

10. Feiereisen P, Duchateau J, Hainaut K. Motor unit recruitment order during voluntary and electrically induced contractions in the tibialis anterior. Exp Brain Res. 1997;114(1):117-23.

11. Ward AR, Shkuratova N. Russian electrical stimulation: the early experiments. Phys Ther. 2002;82(10):1019-30.

12. Currier DP, Lehman J, Lightfoot P. Electrical stimulation in exercise of the quadriceps femoris muscle. Phys Ther. 1979;59(12):1508-12.

13. Currier DP, Mann R. Muscular strength development by electrical stimulation in healthy individuals. Phys Ther. 1983;63(6):915-21.

14. Requena Sánchez B, Padial Puche P, González-Badillo JJ. Percutaneous electrical stimulation in strength training: an update. J Strength Cond Res. 2005;19(2):438-48.

15. Laughman RK, Youdas JW, Garrett TR, Chao EY. Strength changes in the normal quadriceps femoris muscle as a result of electrical stimulation. Phys Ther. 1983;63(4):494-9.
16. Selkowitz DM. Improvement in isometric strength of the quadriceps femoris muscle after training with electrical stimulation. Phys Ther. 1985;65(2):186-96.

17. Soo CL, Currier DP, Threlkeld AJ. Augmenting voluntary torque of healthy muscle by optimization of electrical stimulation. Phys Ther. 1988;68(3):333-7.

18. Valli P, Boldrini L, Bianchedi D, Brizzi G, Miserocchi G. Effect of low intensity electrical stimulation on quadriceps muscle voluntary maximal strength. J Sports Med Phys Fitness. 2002;42:425-30.

19. Westing SH, Seger JY, Thorstensson A. Effects of electrical stimulation on eccentric and concentric torque-velocity relationships during knee extension in man. Acta Physiol Scand. 1990;140(1):17-22.

20. Kramer JF, Semple JE. Comparison of selected strengthening techniques for normal quadriceps. Physiother Can. 1983;35(6):300-4.

21. Zhou S. Chronic neural adaptations to unilateral exercise: mechanisms of cross education. Exerc Sport Sci Rev. 2000;28(4):177-84.

22. Maffiuletti NA, Zory R, Miotti D, Pellegrino MA, Jubeau M, Bottinelli R. Neuromuscular adaptations to electrostimulation resistance training. Am J Phys Med Rehabil. 2006;85(2):167-75.

23. Paillard $\mathrm{T}$, Noe F, Edeline 0 . Effets neuromusculaires de l'électrostimulation transcutanée surimposée et combinée à l'activité volontaire: une revue. Ann Readapt Med Phys. 2005;48:126-37.

24. Baron R. Normative data for muscle strength in relation to age, knee angle and velocity. Wien Med Wochenschr. 1995;145(22):600-6.

25. Moffroid M, Whipple R, Hofkosh J, Lowman E, Thistle H. A study of isokinetic exercise. Phys Ther. 1969;49(7):735-47.

26. Thorstensson A, Grimby G, Karlsson J. Force-velocity relations and fiber composition in human knee extensor muscles. J Appl Physiol. 1976;40(1):12-6.

27. Kannus P. Isokinetic evaluation of muscular performance: implications for muscle testing and rehabilitation. Int J Sports Med Suppl. 1994;15:S11-S18.

28. Wolf S, Ariel GB, Saar D, Penny MA, Railey P. The effect of muscle stimulation during resistive training on performance parameters. Am J Sports Med. 1986;14(1):18-23.

29. Willan PL, Ransome JA, Mahon M. Variability in human quadriceps muscles: quantitative study and review of clinical literature. Clin Anat. 2002;15(2):116-28.

30. Mintken PE, Carpenter KJ, Eckhoff D, Kohrt WM, Stevens JE. Early neuromuscular electrical stimulation to optimize quadriceps muscle function following total knee arthroplasty: a case report. J Orthop Sports Phys Ther. 2007;37(7):364-71. 